Pacific Journal of Mathematics

AN EXTENSION OF SION'S MINIMA THEOREM WITH AN 


\title{
AN EXTENSION OF SION'S MINIMAX THEOREM WITH AN APPLICATION TO A METHOD FOR CONSTRAINED GAMES
}

\author{
JOACHIM HARTUNG
}

Sion's minimax theorem is extended for noncompact sets, and for certain two-person zero-sum games on constrained sets a sequential unconstrained solution method is given.

I. Introduction. It is an important question in two-person zero-sum games, whether there exists a saddle point strategy, and if so, how it is to be computed. Existence theorems are known almost only for the case that the sets of strategies are compact. Often these sets are given by numerically complicated conditions and because of the necessity to consider the boundary of the constraint region you cannot apply analytical methods.

First we extend Sion's minimax theorem [7] for noncompact sets. With it we then give a solution method for a frequently occuring type of games over constrained sets. This method approximates a solution from the interior of the admissible sets and makes it possible to apply analytical methods like those for the whole spaces. It can be regarded as an extension of the widely used Interior Penalty Method of Nonlinear Programming to saddle point problems.

II. A minimax theorem for noncompact sets. Let $X$ and $Y$ be not empty subsets of real linear topological Hausdorff spaces $\mathscr{Z}$ and $\mathscr{Y}$, respectively, and let $\mathbf{R}$ denote the real numbers.

DEFINITION 1.

(a) A function $f: X \rightarrow \boldsymbol{R}$ is called

(i) inf-compact if $\{x \mid x \in X, f(x) \leqq a\}, a \in R$, is compact,

(ii) sup-compact if $\{x \mid x \in X, f(x) \geqq a\}, a \in R$, is compact.

(b) A function $f: X \times Y \rightarrow R$ is called $\left(x_{1}, y_{1}\right)$-sup inf-compact, for a fixed $\left(x_{1}, y_{1}\right) \in X \times Y$, if $f\left(x_{1}, \cdot\right)$ is inf-compact and $f\left(\cdot, y_{1}\right)$ is sup-compact.

If $f: X \times Y \rightarrow R$ is u.s.c.-l.s.c., i.e., $f(x, y)$ is upper semi-continuous in $x$ for each $y \in Y$ and lower semi-continuous in $y$ for each $x \in X$, and $X$ and $Y$ are compact sets, then $f(x, y)$ is $\left(x_{1}, y_{1}\right)$-sup inf-compact for all $\left(x_{1}, y_{1}\right) \in X \times Y$. Thus the following theorem generalizes Theorem 3.4 of Sion [7].

THEOREM 1. Let $X$ and $Y$ be convex sets, and $f: X \times Y \rightarrow R$ an 
u.s.c.-l.s.c. and quasi-concave-convex function, that is $\left(x_{1}, y_{1}\right)$-sup infcompact for a fixed $\left(x_{1}, y_{1}\right) \in X \times Y$. Then we have

$$
\max _{i \in X} \min _{y \in Y} f(x, y)=\min _{y \in Y} \max _{x \in X} f(x, y) \text {. }
$$

Proof. Let $\left(x_{1}, y_{1}\right) \in X \times Y$ with the property given above be fixed.

(i) $L_{1}:=\left\{x \mid x \in X, f\left(x, y_{1}\right) \geqq f\left(x_{1}, y_{1}\right)\right\}$ is compact, $f\left(x, y_{1}\right)$ is u.s.c. in $x$ and $\sup _{x \in X} f\left(x, y_{1}\right)=\sup _{x \in L_{1}} f\left(x, y_{1}\right)$. Since an u.s.c. function on a compact set takes its maximum, there exists $\varphi\left(y_{1}\right):=$ $\max _{x \in X} f\left(x, y_{1}\right)$. Now, for $a \in \boldsymbol{R}$, we have

$$
\begin{aligned}
&\left\{y \mid y \in Y, \sup _{x \in X} f(x, y) \leqq a\right\} \\
& \quad=\bigcap_{x \in X}\{y \mid y \in Y, f(x, y) \leqq a\} \subset\left\{y \mid y \in Y, f\left(x_{1}, y\right) \leqq a\right\} .
\end{aligned}
$$

$\{y \mid y \in Y, f(x, y) \leqq a\}, x \in X$, is closed because $f(x, y)$ is l.s.c. in $y$ for each $x \in X ;\left\{y \mid y \in Y, f\left(x_{1}, y\right) \leqq \alpha\right\}$ is compact because $f\left(x_{1}, y\right)$ is inf-compact in $y$, and thus with $\varphi(y):=\sup _{x \in X} f(x, y)$ the level sets $\{y \mid y \in Y, \varphi(y) \leqq a\} \quad$ are compact. $\quad M_{1}:=\left\{y \mid y \in Y, \phi(y) \leqq \varphi\left(y_{1}\right)\right\} \quad$ is compact and not empty because

$$
\varphi\left(y_{1}\right)=f\left(x^{\prime}, y_{1}\right), \text { for some } x^{\prime} \in X .
$$

$\inf _{y \in Y} \varphi(y)=\inf _{y \in M_{1}} \varphi(y), \varphi(y)$ is l.s.c., and since a l.s.c. function on a compact set takes its minimum, there exists $\min _{y \in Y} \sup _{x \in X} f(x, y)$. Equivalently there exists $\max _{x \in X} \inf _{y \in Y} f(x, y)$.

(ii) Suppose

$$
\sup _{x \in X} \inf _{y \in Y} f(x, y)<k<\inf _{y \in Y} \sup _{x \in X} f(x, y) .
$$

For all $x \in X$ the sets

$$
B_{x}:=\{y \mid y \in Y, f(x, y) \leqq k\}
$$

are closed, and $B_{x_{1}}$ is compact. From (1) it follows that the family of the complements $\left\{B_{x}^{C}\right\}_{x \in X}$ is an open covering of $Y$, for if this were wrong, we would have a $y_{0} \in Y$ with $f\left(x, y_{0}\right) \leqq k$ for all $x \in X$ and thus $\inf _{y \in Y} \sup _{x \in X} f(x, y) \leqq \sup _{x \in X} f\left(x, y_{0}\right) \leqq k$, which contradicts (1). Further we have

$$
Y \subset B_{x_{1}} \cup B_{x_{1}}^{c}
$$

Since the family $\left\{B_{x}^{C}\right\}_{x \in X}$ covers $Y$, it covers also $B_{x_{1}} \cdot B_{x_{1}}$ is compact and thus covered by a finite covering

$$
\left\{B_{x_{c}}^{c}, \cdots, B_{x_{m}}^{C}\right\}, \quad x_{i} \in X, \quad i=2, \cdots, m .
$$

With (2) this means $\left\{B_{x_{1}}^{c}, B_{x_{2}}^{c}, \cdots, B_{x_{m}}^{c}\right\}$ covers $Y$. We have found a 
finite set $X_{1}=\left\{x_{1}, \cdots, x_{m}\right\} \subset X$ such that for each $y \in Y$ there exists an $x \in X_{1}$ with $f(x, y)>k$.

Similarly there exists a finite set $Y_{1} \subset Y$ such that for each $x \in X$ there exists a $y \in Y_{1}$ with $f(x, y)<k$.

Following now the second part of Sion's proof of Theorem 3.4 in [7], we come to a contradiction to (1), and we have

$$
\sup _{x \in X} \inf _{y \in Y} f(x, y)=\inf _{y \in Y} \sup _{x \in X} f(x, y) \text {. }
$$

(iii) Let $\varphi(y):=\sup _{x \in X} f(x, y)$ and $\psi(x):=\inf _{y \in X} f(x, y)$, then by (i) there exist $x_{0} \in X, y_{0} \in Y$ such that

$$
\varphi\left(y_{0}\right)=\inf _{y \in Y} \varphi(y), \quad \psi\left(x_{0}\right)=\sup _{x \in X} \psi(x) .
$$

By (3) we then get, for $x \in X, y \in Y$,

$$
f\left(x, y_{0}\right) \leqq \sup _{x \in X} f\left(x, y_{0}\right)=\varphi\left(y_{0}\right)=\dot{\psi}\left(x_{0}\right)=\inf _{y \in Y} f\left(x_{0}, y\right) \leqq f\left(x_{0}, y\right) .
$$

Putting in (4) $x=x_{0}, y=y_{0}$, we get

$$
f\left(x_{0}, y_{0}\right)=\max _{x \in X} f\left(x, y_{0}\right)=\min _{y \in Y} f\left(x_{0}, y\right),
$$

and thus

$$
\min _{y \in Y} \max _{x \in X} f(x, y)=\max _{x \in X} \min _{y \in Y} f(x, y)
$$

III. A sequential unconstrained solution method. Let $A$ and $B$ be closed convex and not empty subsets of real linear topological Hausdorff spaces $\mathscr{X}$ and $\mathscr{Y}$, respectively, and $f: A \times B \rightarrow \boldsymbol{R}$ may be a payoff function. Then we consider the two-person zero-sum game $(A, B, f)$. A strategy may be called optimal if it is a saddle point component. Let int $A$ denote the interior, cl $A$ the closure and bd $A$ the boundary of $A$. We assume that int $A \neq \varnothing, \operatorname{int} B \neq \varnothing$, such that all points of $A$ and $B$ may be reached from the interior:

$$
\text { clint } A=A, \quad \text { clint } B=B \text {. }
$$

Definition 2. A function $g: \operatorname{int} A \times \operatorname{int} B \rightarrow R$ is called a barrier function of $A \times B$, if

(i ) $g(x, y)$ is bounded above in $x$ for each $y \in \operatorname{int} B$, and bounded below in $y$ for each $x \in \operatorname{int} A$.

(ii) $g(x, y)$ is u.s.c.-l.s.c. on (int $A \times \operatorname{int} B$ ), i.e., the level sets

$$
\{y \mid y \in \operatorname{int} B, g(x, y) \leqq a\}, \quad(x \in \operatorname{int} A, a \in R),
$$

and 


$$
\{x \mid x \in \operatorname{int} A, g(x, y) \geqq a\}, \quad(y \in \operatorname{int} B, a \in R),
$$

are closed.

REMARK. If $A$ and $B$ are compact, and if $g(x, y)$ is u.s.c.-l.s.c. on (int $A \times \operatorname{int} B$ ), the boundedness condition is fulfilled: Let $x^{\prime} \in \operatorname{int} A$ be fixed, then the level sets $L_{y}:=\left\{x \mid x \in \operatorname{int} A, g(x, y) \geqq g\left(x^{\prime}, y\right)\right\},(y \in$ int $B$ ), are not empty, closed and contained in int $A$, and thus compact, when $A$ is compact. Since

$$
\sup _{x \in \operatorname{int} A} g(x, y)=\sup _{x \in L_{y}} g(x, y)=\max _{x \in L_{y}} g(x, y),
$$

there exists $\max _{x \in \operatorname{int} A} g(x, y)$, for each $y \in \operatorname{int} B$.

Now let $g(x, y)$ be a barrier function of $A \times B$, then for a positive real sequence $\left\{r_{n}\right\}_{n \in N} \subset \boldsymbol{R}$, with $r_{n} \rightarrow+0$ for $n \rightarrow \infty$, we define on (int $A \times \operatorname{int} B$ ) the family of payoffs

$$
p_{n}(x, y):=f(x, y)+r_{n} g(x, y), \quad(n \in N) .
$$

THEOREM 2. Let $p_{n}(x, y)$ be quasi-concave-convex on (int $A \times \operatorname{int} B$ ), and $f(x, y)$ be continuous in each variable, quasi-concave-convex, bounded above in $x$ for each $y \in B$, bounded below in $y$ for each $x \in A$, and $\left(x_{0}, y_{0}\right)$-sup inf-compact on $(A \times B)$, for a fixed $\left(x_{0}, y_{0}\right) \in$ (int $A \times$ int $B)$. Then we have:

(i) The game (int $A$, int $B, p_{n}(x, y)$ ), $n \in N$, has optimal strategies $x_{n}$ and $y_{n}$.

(ii) $\left\{x_{n}\right\}_{n \in N}$ and $\left\{y_{n}\right\}_{n \in N}$ have cluster points, and these points are optimal strategies for the game $(A, B, f)$.

Proof. Let $\left(x_{0}, y_{0}\right) \in($ int $A \times \operatorname{int} B)$ with the property given above be fixed.

(i) The function $p_{n}(x, y),(n \in N)$ satisfies the conditions of Theorem 1: By our assumptions on the functions $f$ and $g$ we have the obvious fact that $p_{n}=f+r_{n} g$ is u.s.c.-l.s.c. on (int $A \times \operatorname{int} B$ ); cf. Definition 2.

For $x=x_{0}$ we have

$$
\begin{aligned}
& \left\{y \mid y \in \operatorname{int} B, p_{n}\left(x_{0}, y\right) \leqq a\right\} \\
& \subset\left\{y \mid y \in B, f\left(x_{0}, y\right) \leqq a-r_{n} \cdot \inf _{y \in \operatorname{int} B} g\left(x_{0}, y\right)\right\}=: P_{x_{0}}^{a} .
\end{aligned}
$$

$P_{x_{0}}^{a}$ is compact because $f\left(x_{0}, y\right)$ is inf-compact in $y$. So $p_{n}\left(x_{0}, \cdot\right)$ is inf-compact. Similarly it follows that $p_{n}\left(\cdot, y_{0}\right)$ is sup-compact.

From Theorem 1 we get the existence of a saddle point $\left(x_{n}, y_{n}\right)$ of $p_{n}$ over (int $A \times \operatorname{int} B$ ).

(ii) Denote 


$$
\begin{aligned}
v_{n}:= & p_{n}\left(x_{n}, y_{n}\right)=\operatorname{val}\left(\operatorname{int} A, \operatorname{int} B, p_{n}(x, y)\right), \quad(n \in N), \\
v_{0}:= & \operatorname{val}(A, B, f)=f\left(x^{\prime}, y^{\prime}\right), \text { for a saddle point }\left(x^{\prime}, y^{\prime}\right) \\
& \text { of } f \text { on } A \times B, \text { which exists by Theorem } 1 .
\end{aligned}
$$

We have

$$
\begin{aligned}
f\left(x_{n}, y\right)+r_{n} g\left(x_{n}, y\right) \geqq v_{n}, & \text { for each } y \in \operatorname{int} B, \\
f\left(x, y_{n}\right)+r_{n} g\left(x, y_{n}\right) \leqq v_{n}, & \text { for each } x \in \operatorname{int} A, \\
f\left(x^{\prime}, y\right) \geqq v_{0}, \quad f\left(x, y^{\prime}\right) \leqq v_{0}, & \text { for each } x \in A \text { and } y \in B .
\end{aligned}
$$

For an arbitrary but fixed real $\delta>0$ let $x_{\delta} \in \operatorname{int} A$ and $y_{\delta} \in \operatorname{int} B$ be $\delta$-optimal strategies in the game $(A, B, f)$ :

$$
\begin{aligned}
f\left(x_{\delta}, y\right) \geqq v_{0}-\delta, \quad f\left(x, y_{\delta}\right) \leqq & v_{0}+\delta, \\
& \text { for each } x \in A, \quad y \in B .
\end{aligned}
$$

From (1), (2) and (3) we get

$$
\begin{aligned}
& {\left[f\left(x_{\delta}, y_{n}\right)+r_{n} g\left(x_{\delta}, y_{n}\right)\right]-f\left(x_{\delta}, y_{n}\right)-\delta} \\
& \quad \leqq v_{n}-v_{0} \leqq\left[f\left(x_{n}, y_{\delta}\right)+r_{n} g\left(x_{n}, y_{\delta}\right)\right]-f\left(x_{n}, y_{\delta}\right)+\delta,
\end{aligned}
$$

and

$$
r_{n} g\left(x_{\delta}, y_{n}\right)-\delta \leqq v_{n}-v_{0} \leqq r_{n} g\left(x_{n}, y_{\delta}\right)+\delta \text {. }
$$

The boundedness of $g$ then implies

$$
r_{n} \cdot \inf _{y \in \operatorname{int} B} g\left(x_{\delta}, y\right)-\delta \leqq v_{n}-v_{0} \leqq r_{n} \cdot \sup _{x \in \operatorname{Int} A} g\left(x, y_{\delta}\right)+\delta,
$$

and for $r_{n} \rightarrow+0,(n \rightarrow \infty)$,

$$
-\delta \leqq \liminf _{n \rightarrow \infty}\left(v_{n}-v_{0}\right) \leqq \limsup _{n \rightarrow \infty}\left(v_{n}-v_{0}\right) \leqq \delta .
$$

Since $\delta>0$ is arbitrarily chosen, that gives

$$
\lim _{n \rightarrow \infty} v_{n}=v_{0} \text {. }
$$

From (1) we get for each $y \in \operatorname{int} B$

$$
\begin{aligned}
f\left(x_{n}, y\right) & \geqq v_{n}-r_{n} g\left(x_{n}, y\right) \\
& \geqq v_{n}-r_{n} \cdot \sup _{x \in \operatorname{int} . A} g(x, y),
\end{aligned}
$$

and since $v_{n} \rightarrow v_{0}, r_{n} \rightarrow 0,(n \rightarrow \infty)$, there exists a constant $c$ independent of $n$ such that

$$
f\left(x_{n}, y_{0}\right) \geqq c, \text { for all } n \in N \text {. }
$$

$f\left(\cdot, y_{0}\right)$ is sup-compact, so $\left\{x_{n}\right\}_{n \in N}$ is contained in a compact set. 
Hence there exists a subset $\left\{x_{n(\alpha)}\right\}$ of the sequence $\left\{x_{n}\right\}$ which converges to an $\hat{x} \in A$. With (5) and (4) we get for each $y \in \operatorname{int} B$ by $x_{n(x)} \rightarrow \widehat{x}$

$$
\begin{aligned}
f(\widehat{x}, y) & =\lim f\left(x_{n(\alpha)}, y\right) \\
& \geqq \lim \left(v_{n(\alpha)}-r_{n(\alpha)} \cdot \sup _{\alpha \in \ln \mathrm{d} A} g(x, y)\right) \\
& \geqq \lim v_{n(\alpha)}=v_{0} .
\end{aligned}
$$

$f(\hat{x}, y)$ is continuous in $y$ and thus (6) provides

$$
f(\widehat{x}, y) \geqq v_{0}, \text { for all } y \in B \text {; }
$$

i.e., $\hat{x}$ is an optimal strategy for $(A, B, f)$.

Corollary. For every sequence $\left\{r_{n}\right\}_{n \in N} \subset R, r_{n} \rightarrow+0,(n \rightarrow \infty)$, the values $v_{n}=\operatorname{val}\left(\operatorname{int} A\right.$, int $B, f+r_{n} g$ ) converge to the value $v_{0}=$ $\operatorname{val}(A, B, f)$, and if $(A, B, f)$ has a unique solution, the whole sequences of corresponding optimal strategies $\left\{x_{n}\right\}_{n \in N},\left\{y_{n}\right\}_{n \in N}$ converge to the solution of $(A, B, f)$.

The solution method is now: Construct a barrier function $g$ of $A \times B$, choose a positive nullsequence $\left\{r_{n}\right\}_{n \in N} \subset \boldsymbol{R}$, build $p_{n}=f+r_{n} g$, find an optimal strategy $x_{n}$ of (int $A$, int $B, p_{n}(x, y)$ ) and take a cluster point of $\left\{x_{n}\right\}_{n \in N}$ as an optimal strategy for $(A, B, f)$, on the premises that the conditions of Theorem 2 are satisfied.

An example: Let $A$ and $B$ be given by

$$
\begin{aligned}
& A=\left\{x \in \mathscr{Z} \mid G_{i}(x) \leqq 0, i=1, \cdots, m\right\}, \\
& B=\left\{y \in \mathscr{Y} \mid H_{j}(y) \leqq 0, j=1, \cdots, n\right\},
\end{aligned}
$$

with some continuous convex functions

$$
\begin{aligned}
& G_{i}: \mathscr{Z} \longrightarrow \boldsymbol{R}, \quad(i=1, \cdots, m), \\
& H_{j}: \mathscr{Y} \longrightarrow \boldsymbol{R}, \quad(j=1, \cdots, n) .
\end{aligned}
$$

Under the hypothesis that

$$
\begin{aligned}
& \operatorname{int} A=\left\{x \in \mathscr{X} \mid G_{i}(x)<0, i=1, \cdots, m\right\} \neq \varnothing \\
& \operatorname{int} B=\left\{y \in \mathscr{Y} \mid H_{j}(y)<0, j=1, \cdots, n\right\} \neq \varnothing,
\end{aligned}
$$

we can take as barrier functions of $A \times B$ for example:

$$
\begin{aligned}
& g_{1}(x, y):=\sum_{i=1}^{m} \lg \left(-\max \left[G_{i}(x),-1\right]\right)-\sum_{j=1}^{n} \lg \left(-\max \left[H_{j}(y),-1\right]\right), \\
& g_{2}(x, y):=\sum_{i=1}^{m} \frac{1}{G_{i}(x)}-\sum_{j=1}^{n} \frac{1}{H_{j}(y)} .
\end{aligned}
$$


Both are well defined on int $A \times \operatorname{int} B$.

$$
h_{1 j}(y):=-\lg \left(-\max \left[H_{j}(y),-1\right]\right) \text { and } h_{2 j}(y):=-\frac{1}{H_{j}(y)}
$$

are convex, bounded below by 0 and 1.s.c. on $\operatorname{int} B$; so $\sum_{j=1}^{n} h_{k j}(y)$ has these properties, too, $(k=1,2)$. If $B$ is compact, we can take also $h_{1^{\prime} j}(y):=-\lg \left(-H_{j}(y)\right)$, which then gives the mostly used barrier functions in the Interior Penalty Method of Nonlinear Programming, tracing back to Frisch [5] and Caroll [2], respectively.

IV. Computational aspects. In the differentiable case, a necessary and for a (strictly quasi-) concave-convex function $h(x, y)$ sufficient condition in order that $(\bar{x}, \bar{y})$ is a saddle point of $h(x, y)$ over open (convex) sets, is

$$
(*) \quad \frac{\partial h(\bar{x}, \bar{y})}{\partial x}=0, \quad \frac{\partial h(\bar{x}, \bar{y})}{\partial y}=0 .
$$

(If the sets include their boundaries, the condition is much more complicated (cf. [3]).) In our method at each stage $\left(r_{n}\right)$ we have to solve such a system $(*)$ for $p_{n}(x, y)$.

This can be done by fixpoint methods, like the Newton Method or its modifications.

We can also take the gradient methods of [1] or [3] to solve (int $A$, int $B, p_{n}$ ) directly.

All the methods need a starting point in the interior of the regions. Mostly such a point is known in advance, but if not, it can be computed by a method given in [4], p. 195. Then none of the algorithms mentioned above leaves the interior of the sets $A$ and $B$ because of the boundary properties of the barrier function. Thus the algorithms work as on the whole spaces so that it is justified to call our method a (sequential) unconstrained solution method.

Acknowledgment. The author would like to thank the referee for helpful suggestions.

\section{REFERENCES}

1. K. J. Arrow, L. Hurwicz and H. Uzawa, Studies in Linear and Non-Linear Programming, Part II, Stanford University Press, Stanford (California), 1958.

2. C. W. Caroll, The created response surface technique for optimizing non-linear restrained systems, Oper. Res., 92 , (1961), 169-184.

3. V. F. Dem'janov, Successive approximations for finding saddle points, Soviet Math. Dokl., 8 6, (1967), 1350-1353.

4. A. V. Fiacco and G. P. McCormick, Non-Linear Programming: Sequential Unconstrained Minimization Techniques, Wiley, New York, 1968. 
5. K. R. Frisch, The logarithmic potential method of convex programming, Memorandum of May 13, 1955, University Institute of Economics, Oslo.

6. F. A. Lootsma, A Survey of Methods for Solving Constrained Minimization Problems via Unconstrained Minimization, in: Numerical Methods for Non-Linear Optimization, ed. F. A. Lootsma, Academic Press, London/New York 1972, 313-347.

7. M. Sion, On General Minimax Theorems, Pacific J. Math., 8 (1958), 171-176.

Received January 21, 1980 and in revised form September 23, 1981.

UNIVERSITÄT DORTMUND

POSTFACH 500500

D-4600 DORTMUND 50

WeST GERMANY 


\title{
PACIFIC JOURNAL OF MATHEMATICS
}

\section{EDITORS}

\author{
DONALD BABBITT (Managing Editor) \\ University of California \\ Los Angeles, CA 90024 \\ Hugo Rossi \\ University of Utah \\ Salt Lake City, UT 84112 \\ C. C. MOORE and ARthur Agus \\ University of California \\ Berkeley, CA 94720
}

J. DUGUNDJI

Department of Mathematics

University of Southern California

Los Angeles, CA 90007

R. FINN and J. MILGRAM

Stanford University

Stanford, CA 94305

\section{ASSOCIATE EDITORS}
R. ARENS
E. F. BeCKENBACH
B. H. NeumanN
F. WoLF
K. YoSHIDA

\section{SUPPORTING INSTITUTIONS}

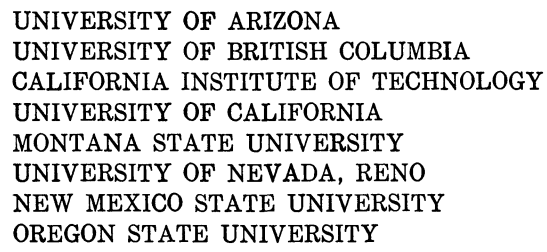

UNIVERSITY OF ARIZONA

UNIVERSITY OF BRITISH COLUMBIA

CALIFORNIA INSTITUTE OF TECHNOLOGY

UNIVERSITY OF CALIFORNIA

MONTANA STATE UNIVERSITY

UNIVERSITY OF NEVADA, RENO

NEW MEXICO STATE UNIVERSITY

OREGON STATE UNIVERSITY

\author{
UNIVERSITY OF OREGON \\ UNIVERSITY OF SOUTHERN CALIFORNIA \\ STANFORD UNIVERSITY \\ UNIVERSITY OF AAWAII \\ UNIVERSITY OF TOKYO \\ UNIVERSITY OF UTAH \\ WASHINGTON STATE UNIVERSITY \\ UNIVERSITY OF WASHINGTON
}

The Supporting Institutions listed above contribute to the cost of publication of this Journal, but they are not owners or publishers and have no responsibility for its content or policies,

Mathematical parers intended for publication in the Pacific Journal of Mathematics should be in typed form or offset-reproduced, (not dittoed), double spaced with large margins. Please do not use built up fractions in the text of the manuscript. However, you may use them in the displayed equations. Underline Greek letters in red, German in green, and script in blue. The first paragraph or two must be capable of being used separately as a synopsis of the entire paper. Please propose a heading for the odd unmbered pages of less than 35 characters. Manuscripts, in triplicate, may be sent to any one of the editors. Please classify according to the scheme of Math. Reviews, Index to Vol. 39. Supply name and address of author to whom proofs should be sent. All other communications should be addressed to the managing editor, or Elaine Barth, University of California, Los Angeles, California, 90024.

50 reprints to each author are provided free for each article, only if page charges have been substantially paid. Additional copies may be obtained at cost in multiples of 50 .

The Pacific Journal of Mathematics is issued monthly as of January 1966, Regular subscription rate: $\$ 114.00$ a year (6 Vol., 12 issues). Special rate: $\$ 57.00$ a year to individual members of supporting institution.

Subscriptions, orders for numbers issued in the last three calendar years, and changes of address shoud be sent to Pacific Journal of Mathematics, P.O. Box 969, Carmel Valley, CA 93924, U.S.A. Old back numbers obtainable from Kraus Periodicals Co., Route 100, Millwood, NY 10546.

PUBLISHED BY PACIFIC JOURNAL OF MATHEMATICS, A NON-PROFIT CORPORATION

Printed at Kokusai Bunken Insatsusha (International Academic Printing Co., Ltd.). 8-8, 3-chome, Takadanobaba, Shinjuku-ku, Tokyo 160, Japan. 


\section{Pacific Journal of Mathematics}

\section{Vol. 103, No. $2 \quad$ April, 1982}

Alberto Alesina and Leonede De Michele, A dichotomy for a class of positive

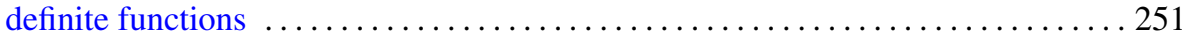

Kahtan Alzubaidy, Rank 2 -groups, $p>3$, and Chern classes . . . . . . . . . . 259

James Arney and Edward A. Bender, Random mappings with constraints on

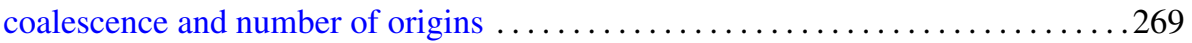

Bruce C. Berndt, An arithmetic Poisson formula . . . . . . . . . . . . . . . 295

Julius Rubin Blum and J. I. Reich, Pointwise ergodic theorems in 1.c.a. groups . . . 301

Jonathan Borwein, A note on $\varepsilon$-subgradients and maximal monotonicity . . . . . . . 307

Andrew Michael Brunner, Edward James Mayland, Jr. and Jonathan Simon,

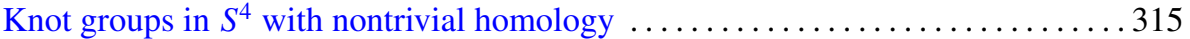

Luis A. Caffarelli, Avner Friedman and Alessandro Torelli, The two-obstacle

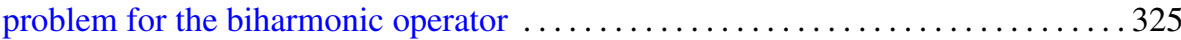

Aleksander Całka, On local isometries of finitely compact metric spaces . . . . . . 337

William S. Cohn, Carleson measures for functions orthogonal to invariant

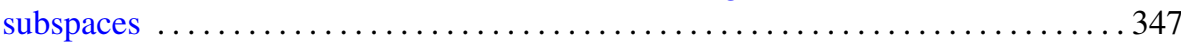

Roger Fenn and Denis Karmen Sjerve, Duality and cohomology for one-relator

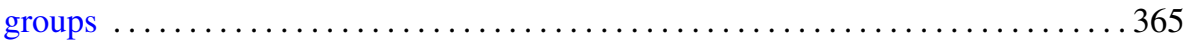

Gen Hua Shi, On the least number of fixed points for infinite complexes . . . . . . . 377

George Golightly, Shadow and inverse-shadow inner products for a class of linear

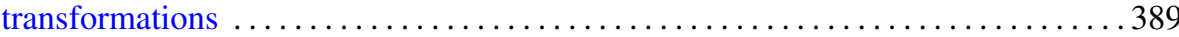

Joachim Georg Hartung, An extension of Sion's minimax theorem with an

application to a method for constrained games $\ldots \ldots \ldots \ldots \ldots \ldots \ldots \ldots \ldots \ldots . \ldots 4$

Vikram Jha and Michael Joseph Kallaher, On the Lorimer-Rahilly and

Johnson-Walker translation planes

Kenneth Richard Johnson, Unitary analogs of generalized Ramanujan sums .

Peter Dexter Johnson, Jr. and R. N. Mohapatra, Best possible results in a class of inequalities

Dieter Jungnickel and Sharad S. Sane, On extensions of nets

Johan Henricus Bernardus Kemperman and Morris Skibinsky, On the

characterization of an interesting property of the arcsin distribution ...

Karl Andrew Kosler, On hereditary rings and Noetherian $V$-rings

William A. Lampe, Congruence lattices of algebras of fixed similarity type. II . . . . 475

M. N. Mishra, N. N. Nayak and Swadeenananda Pattanayak, Strong result for real zeros of random polynomials

Sidney Allen Morris and Peter Robert Nickolas, Locally invariant topologies on free groups

Richard Cole Penney, A Fourier transform theorem on nilmanifolds and nil-theta functions

Andrei Shkalikov, Estimates of meromorphic functions and summability theorems

László Székelyhidi, Note on exponential polynomials

William Thomas Watkins, Homeomorphic classification of certain inverse limit spaces with open bonding maps $\ldots \ldots \ldots \ldots \ldots \ldots \ldots \ldots$

David G. Wright, Countable decompositions of $E^{n}$

Takayuki Kawada, Correction to: "Sample functions of Pólya processes" .

Z. A. Chanturia, Errata: "On the absolute convergence of Fourier series of the 